sister. The boy, as soon as he is old enough to be around, is dressed so that he can run, jump or turn heels over head; in fact, his movements are not interfered with in any way, either by dress or custom, but how is it with his sister? Whatever of liberty there is left after the method of dressing is taken from her by custom and the fear of being considered immodest. I think the little girl was right, who, when reproved for turning heels over head in the front yard, said, "if people did not want to see her, they must not go by when she was turning heels over head." She had the true sense of woman's rights-the right to be healthy and enjoy health in physical recreation.

Children should be well fed, and these neurotic ohildren, as a rule, are poor eaters, both in quality and quantity. They should be confined to plain, nourishing food, and then forced to eat it. People often tell us they cannot get their children to eat, and are surprised when you insist upon their being made to eat; but I have had the pleasure of seeing several of these rapidly improve under judicious feeding. One case I will briefly describe: She was a delicate, nervous little girl, who was thin and anemic, unable to sleep at night because of nervousness. She wanted no breakfast, unless it were a cracker or a cookie, scarcely any dinner excepring dessert, but at supper she generally did eat a little better. She was absoIutely forced to eat a large dish of oatmeal and milk, without sugar, each morning; a dinner of bread and butter, potatoes and eggs or meat, and drink a glass of milk, no dessert; for supper, she had a dish of oatmeal and milk, bread and butter and some kind of sauce, generally stewed fruit, either dried or fresh. Besides this diet she was allowed plenty of fruit, und was sent early to bed. She has been on this stuffing treatment for nearly two years, and is nuw strong, does her school work easily and well, never has head. ache, sleeps well, except that she gets up early in the morning. This child's poor health was attributed to going to school, as is done in a number of cases, and the children are kept out of school. I think there is no question but that their school work is too much for them in their physicial condition, but too often this condition is caused more by the improper home life than the school life.

Neurotic children suffer greatly from competitive examinations at school, and from the extra work that is often imposed upon them in preparing for school entertainments -especially in preparing for public recitations. I knew one young girl of 13 or 14 years of age who was standing her school work well till she was selected for an important part in some special exercise. She was impressed with the importance of her part, and from the careful drilling she got she became frightened and nervous, and finally ended by going into a hysterical faint after one of these drills. It was a year and a half before she was able to go to school again, and she had during that time vertigo and other hysterical manifestations. At the end of this period she started to school, but she has never been allowed to do any but regular work, which she has accomplished with ease.

I have not referred to the medicinal treatment, for it has been quite thoroughly impressed on my mind that drugs are seldom indicated, and their value is questionable. The price of healthy children is the same as that of Liberty-Eternal Vigilance-and unless parents and physicians are willing to pay that price, we can not expect to avoid hysteria and many of its relatives.

\section{ORIFICIAL IRRITATION IN RELATION TO NEURAL DISTURBANCES.}

Presented to the Section on Neurology and Medical Jurisprudence, at the Forty-ninth Annual Meeting of the American Medical Association, held at Denver, Colo., June 7-10, 1898.

BY GEO. V. I. BROWN, M.D., D.D.S., C.M.

DEAN AND PROFESSOR OF ORAL SURGERY, DENTAL DEPARTMENT MILWAUKEE MEDICAL COLLEGE. MILWAUKEE, WIS.

It would seem, upon consideration, that many operations brought forward by the gynecologists during the last fow years for relief of so-called reflex pains and other nervous disorders, particularly neuralgia and migrainoid headaches, have not given the relief that was promised for them. The same is undoubtedly true to a considerable extent in regard to the rectal surgeon's efforts, and notwithstanding the fact that deviating septa and hypertrophied turbinates have freely given off their offending portions, there still remain many who suffer constantly without a hope of relief; and in directing your attention into a new channel with regard to etiology and treatment of these conditions, I would urge the fact that, with a high nervous organization and free distribution of nervesupply quite as complex as that of the other orifices referred to, the normal mouth has thirty-two teeth as additional predisposing factors, each with its own separate nerve-fibers from the wide-spreading carrier of sensation - the trigeminus. In addition to these connections each root is surrounded by a highly vascular peridental membrane, also in close connection with the blood- and nerve-supply, making it not unreasonable to suppose that all these taken together would offer a very frequent source of irritation. Con. sidering also the fact that through caries the pulps of these teeth and the nerve elements they contain are often exposed directly to external irritants, the etiologic factors, particularly with affections within the range of the direct nerve-supply through which they carry the sensation, ought in a large number of cases to be found to be within the oral cavity. That this is often true without being suspected, through misleading symptoms, the trouble being treated as having its origin in some other of the orifices, will be shown, I think, by the cases described later.

Literature upon the subject of this and kindred disorders is very vague. We find neurasthenia, anemia and numerous other emias, held in a general way to be reponsible, and the recommended treatment beyond certain limitations, also becomes very general, depending chiefly upon general constitutional care, which is all very well so far as it goes, but as a rule the patients suffer on just the same. It is evident to those sufficiently interested to be more than casual observers that in close study of the symptomatology of those affections, with a view to discovering certain definite causes of irritation and the mode of procedure best calculated in each particular case to remove the etiologic factors, lies hope of relief. During the last few years my efforts have been directed to the study of certain peculiar forms of trifacial irritation, particularly one form of which little or nothing in the way of description seems to be extant in the literature of the subject.

Without attempting to go into a general or even a partially detailed description of the various possible irritations from within the oral cavity, I desire to treat. of what I have found to be a very common associate. of neural disorders. It is a noticeable fact that in the 
mouths of all those so affected, wherever the natural teeth remain, their occlusal surfaces show that constant grinding and rubbing has abraded them, through the extreme pressure brought to bear during the paroxysms - if the pain be paroxysmal occurring in an intense nervous state-the result of hours of painful suffering or other like conditions. This has frequent mention by writers as noticeable among those who suffer from such disorders, but in no instance do I find where an author has thought fit to reverse the order of things and make the habit of the jaws, which is responsible for this condition, one of the etiologic factors in bringing about the disease, rather than a result, as it is generally held to be. Last year, before the Section of Stomatology, I described this hyperkinetic condition of the muscles of mastication and explained how irritation of the brain-centers governing these muscles, whether as a symptom of other neural disturbance or vice versa, would produce the same result, namely, an irritation of the peridental membrane surrounding the roots of the teeth, and how, through their apical formina, this irritation might be communicated to the many branches of the nerve, after which, as is well understood, the point at which that result expressed itself in pain, muscular spasm, tenderness of neuritis, hyperesthesia, anesthesia, or whatever the effect might be, could be reflected anywhere along the path of the nerve among its associates. Certain forms of this peridental inflammation and the resulting pain are quite familiar to dentists, but that there was grave trouble frequently caused by other forms of this affection, with which neither they nor physicians were commonly familiar, I have long been satisfied, and in the paper referred to I described a number of cases of extremely aggraviated pain in the head and face, which were cured, or to a considerable extent relieved, at my hands, by the simple method of grinding the crowns of the particular teeth affected in such a manner that they could no longer be brought together. Since the writing of that paper, however, and during the last few months, through my connection with Trinity Hospital in Milwaukee, another form of this particular trouble has come to my notice in several cases, with symptoms such as are commonly ascribed to reflex expressions of uterine diseases, and it is to these that I purpose calling your attention.

In order that something may be understood of the manner of the operation of the jaws, which makes this possible, a little description of their anatomic relations, with particular reference to the development of this idea seems to be in order. Through the ptery. goids a lateral grinding motion of the jaw of man takes place, which if pursued at night is easily noticed, and usually attention is called to it. If, however, the masseter and temporal muscles are called into unusual activity, the result is that the jaws are pressed firmly and tightly together, with a force varying in individuals from 200 to 270 pounds. With the jaws closed normally and the occlusion perfect, this force would be comparatively equally divided among the whole number of teeth. If, however, as usually happens in these cases, the jaws be shifted a little to one side or slightly forward or backward, then certain portions of individual teeth are brought together, and they alone must bear this tremendous force. Ordinarily the membrane surrounding the root is capable of withstanding a considerable amount of pressure for a considerable length of time. But by the continued application of this pressure, especially when weakened by other more general conditions, as of circulation or otherwise, this power of resistance becomes impaired and then one of two things must result-either a local disturbance made manifest by elongation of the tooth and soreness to pressure, a not generally serious affection, accompanied sometimes by localized pain, usually comparatively easily remedied, or as I have believed, a direct communication of this irritation to the larger nerve trunks, to be by them carried to other parts. It has been recently proven that the old idea -as given in Gray's and other anatomies - of a direct communication of artery, vein and nerve, from the apical foramen to the main trunk of the nerve, passing along the jaw, is generally, if not always, incorrect, and that there is a more complex nervous connection with nerve filaments extending directly from this membrane to the main nerve supply, and this scientific histologic demonstration is directly in line with my own clinical observation, because it explains at once what I believe I have demonstrated to be true: that any or all the nervous symptoms generally recognized can be the direct result of peripheral irritation through this peridental membrane. We are all familiar with the much-written and widely understood neural disturbances consequent upon eye-strain, but whoever heard of neurasthenia, hysteria or neuralgia resulting from jaw-strain, and yet this is exactly what does occur. If the use of certain muscles and the straining of those muscles cau cause neurotic symptoms through irritation of the optic nervo-supply, why can not the continued application of hundreds of pounds of force directly to certain other branches of the nerve through which sensation is transmitted do so equally with the other part. This theoretic explan. ation is, I believe, borne out quite fully by the fol. lowing cases which, for example, I desire to describe:

Case 1.-Mrs. - complained of a general debility, lose of strength and poor circulation, and suffered intense pain at rather short intervals, which finally became shorter until the pain was almost continuous between her eyes at the base of the brain and in the vicinity of the ear upon the left side. Three operations by gynecologists, who had mistaken her symptoms for reflex pain due to some womb disorder, left her rather worse than better. The treatment of certain inflamed conditions of the pulps of her teeth and maxillary sinus, and a correction by grinding the surfaces of tooth crowns, giving evidence of receiving rather more than their share of the wear and tear has given her, at least for the few months past since the operation, complete relief.

Case 2.-Mrs. , a very great sufferer, pain in eyes, back of the head, which during severe paroxysms was severely felt also in the back, arms and leg, had become almost a hopeless neurasthenic. The birth of the last of her five children was coincident with the onset of the severe symptoms and naturally led to treatment for laceration and endometritis, but without result. The abraded crowns of several teeth and the set expression during pain facilitated diagnosis ; the treatment applied was to grind the occlusal surfaces of the affected teeth until they could not meet iu occlusion, and treatment of pulps of the teeth that were irritated, resulting in complete relief from pain and a generally improved condition.

Two cases were reported in the paper before referred to, one in which hyperesthesia of the lower lip and chin was instantly relieved by the extraction of a bicuspid tooth of a woman who had been treated, as she said, "for falling of the womb"; and another, a girl about 17 years old, whose extreme suffering for about eighteen months was finally relieved by grinding down certain teeth, irritated by grinding at night, found to be the probable result of sexual excitement as shown by a history of the case.

Many similar instances might be recited in which the symptoms of pathologic oral conditions have been 
confused with those of the eye, ear, nose and rectum, as well as of the vagina and uterus, but the present purpose is chiefly to call attention to the fact that this habit of the muscles of the jaws is of extremely common occurrence-in fact, nearly always an active feature of nervous states-for if caused, as sometimes happens, by overstimulus of the centers controlling those muscles, the result of some etiologic excitement elsewhere, then the effect is simply to inorease the severity of symptoms; on the other hand, it may be the irritant, and solely responsible, but in either case the simple attention necessary to correction of the difficulty is a matter of first necessity in the treatment of a large majority of sufferers from functional and other disorders of the nervous system.

\section{NERVOUSNESS AN ELEMENT IN HYPERPYREXIA.}

Presented to the Section on Neurology and Medical Jurisprudence, at the Forty-ninth Annual Meeting of the American Medical Association, held at Denver, Colo., June 7-10, 1898. BY C. C. HERSMAN, M.D.

Lecturer on Mental and Nervous Diseases, Western University of Penn sylvania, Medical Department; Physician to St. Francis Hospi-

tal, Insane Department; Alienist and Neurologist, South Side Hospital, Pittsburg. PITTSBURG, PA.

Temperature, from Hippocrates down, has been recognized as a factor in disease. In the present paper the topic is to be discussed with reference to the explosive (nerve-storm-like) and sudden elevation of temperature under certain mental impressions or conditions.

Musser attributes the stability of temperature to the central regulating apparatus, called the thermotoxic apparatus. This aggregation of forces is under the control of the nervous system, either through the motor or special nerves which pass with them to and from definite centers in the brain, called heat centers. He claims that the elevation of temperature is due to the increased disintegration of nitrogenous tissue. It has also been said that the high range is caused by the taking in of more poison than is gotten rid of, or, to give bacteriologic zest to the expression, the microbes are in competition with the corpuscles of the blood.

High temperatures are not so dangerous, or so uniformly fatal, as low. Da Costa records a recovery from a temperature of $110 \mathrm{~F}$. in the axilla, following cerebral rheumatism. Teal reports a case of recovery from a spinal injury with a range of temperature of 112 to 114 F., which continued for days. Dr. J. B. Murdoch of Pittsburg, formerly Dean of the Medical Department of the Western University of Pennsylvania, admitted a case to the Western Pennslyvania Hospital Dec. 13, 1893, whose temperature on the eighth, ninth, tenth and eleventh days was respectively 112, 114.8, 119 and $120 \mathrm{~F}$. His patient had hysteric symptoms and he, with others of the staff who saw the case, decided that the hysteria was the cause of the high temperature. The cause of these high temperatures is mere conjecture. The increased disintegration of nitrogenous tissue and the microbes in competition with the blood corpuscles can not be relied on.

Experiments upon dogs have shown that to irritate certain centers of the brain will control temperature, while destruction of the center will cause a high rise. I have thought that a hyperesthetic condition of the heat center might answer for the cause, but according to the irritation theory, nothing short of a paralysis of the center could cause the rise, while the hyperesthesia would control it. In the following cases the last thing mentioned could be the only plausible one to me:

Case 1.-K. R., aged 21, American, nurse. Disease diagnosed as spinal meningitis. Admitted to South Side Hospital Dec. 4, 1897. Family history negative. Personal history, typhoid two or three years prior. During the course of the disease she complained severely of a pain in back of head. Delirium marked. Three months ago confined to bed with severe pain around cecum and caput coli, with some inflation. No elevation of temperature, but nervous, with inclination to hysteric aymptoms.

Present trouble began with severe headache, with boring pain in back of neck, followed by numerous chills and muscles of back of neck rigid, with head slightly drawn back, tendernese along spine and mild delirium. Retention of urine. At times evening temperature $107 \mathrm{~F}$., but was promptly reduced in a very few minutes with ice sponge. Antipyretics had little effect. Pulse at times very weak. On the seventh day the temperature was highest, $118 \mathrm{~F}$.

At times the temperature would drop from $110 \mathrm{~F}$. to normal in a very few (twenty) minutes without interference, but mostly the sponge bath was resorted to with very prompt effect. Usually when she had the high temperatures she had marked hysteric symptoms. The fever always abated most rapidly when treated by those in whom she had most faith and liked best. A visit from friends would provoke an attack, seemingly, to me, to show how sick she was.

My diagnosis differed from those who had preceded me, as I could see nothing but a very exaggerated nervous condition attended by hyperpyrexia and hysteric symptoms. At the end of fifteen days sho was sent home.

Case 2.-Lizzie N., aged 29, Irish, domestic. In United States eight yeare. Admitted to South Side Hospital of Pittsburg, Dec. 10, 1897, her disease having been diagnosed articular rheumatism of one week's duration, which was ushered in by a chill.

On admission temperature $99 \mathrm{~F}$., pulse 102, respiration 24. Joints sore and very tender, especially the knees. On the second day after admission the temperature became normal. On the fourth day $104 \mathrm{~F}$., eighth and ninth days normal. On the thirteenth day normal, but on the fourteenth it rose to 106.2 , pulse 80 . On the eighteenth day 110.9 , pulse 80 ; twenty-third day $11: 30$ AM., 110, but at $2: 30$ P.M. had dropped to 99 , pulse 80. At various times from the eighteenth to the twenty-third day the thermometer registered 110.

On the thirty.fourth day of the disease the register was 112 . On the thirty.fifth day at $11: 30 \mathrm{~A} . \mathrm{M}$. I took her temperature under the tongue at $116 \mathrm{~F}$. with a pulse of 80 and a cool skin, and twenty minutes after I left the ward it was registered at 102 by another thermometer. On the forty-second day after admission the thermometer registered 118.4. Her temperature for the past fow days ran along from 105 to 108 , occasionally down as low as 104 , and once to 103 . This continued up to the sixty-ninth day, when the temperature dropped to 99 , following a chill, but soon to return to its old haunts, 108 to 110 . This high range continued until the eighty-sixth day, when at $3: 20$ A.M. it registered 98 , but again went back to 107.4 , which continued until the ninety-third day, when she became dissatisfied and asked permission to leave the hospital, which was granted.

She left with a temperature of 104.8 and walked with slight assistance to the street-cars, three squares away, but on the evening of the same day she returned slightly intoxicated and asked to be readmitted. Her temperature was then 97.4. On the second day after readmission her temperature was 108, on the third 110 , on the fifth 112.4 , on the sixth, A.M. 97 , but at $1: 20$ P. M. was again at 111.2; on the seventh 97 , but on the eighth was 108, at which time she was sent out of the hospital, 101 days after her first admission.

She went to the home of her former employer, where she remained for about ten days, going about the house, and occasionally going out. On attempting to alight from a street-car she broke her ankle and was sent to a hospital. Her improvement has been continuous and her temperature has never been above 99.4 F. Usually it has been normal. In the first hospital her rest at night was very much broken. Sometimes she would sleep all night, at others lie awake until 3 or 4 o'clock in the morning. If the interne not in attendance on her would administer her hypnotic she would be likely to lie awake all night watching for "her doctor," to find out whether the 